\title{
Study of Voltage Stability of a Multi-bus System Before and After Compensation
}

\author{
B Venkateshnaik ${ }^{1}$, Dr. D. Sathyanarayana ${ }^{2}$ \\ Student, Power System Department, University of BDT College of Engineering, Davanagere, India ${ }^{1}$ \\ Professor Power System Department, University of BDT College of Engineering, Davanagere, India ${ }^{2}$
}

\begin{abstract}
In this to a great extent developing universe of energy framework keeping up voltage dependability is extremely troublesome errand on the grounds that as the span of the power framework organize expands the odds of event of blame additionally increments. In intensely stacked frameworks, voltage dependability farthest point is generally overwhelming and voltage precariousness is typically watched taking after expansive aggravation. In this paper an exertion is made with a specific end goal to keep up the voltage soundness of multi transport framework by controlling the receptive power stream in the framework. Ideal receptive power stream in the system is the key component of voltage dependability of the framework. The repaying gadgets utilized as a part of this paper are STATCOM which is shunt remunerating gadget and DVR which is arrangement remunerating gadget. A NR procedure is utilized to direct the LFS and thus the weakest transport is dictated by the LFS. A relative investigation of arrangement and shunt pay is made. The exhibitions of above repaying gadgets are done on a standard IEEE 14 transport framework. MATLAB/Simulation is utilized to investigate the execution.
\end{abstract}

Keywords: STATCOM-static synchronous compensator, DVR-dynamic voltage restorer. VSM-voltage stability margin, MLP-greatest pinnacle loading. LFS-stack stream considers.

\section{INTRODUCTION}

As the need of deregulation for overall electric utility enterprises, utility transmission frameworks are moving toward their points of confinement. This makes the requirement for solid power more prominent than any time in recent memory. In deregulation condition, the requirement for new power stream controllers to upgrade transmission line ability will increment. Primarily, these new controllers ought to have the capacity to control voltage level and increment control stream ability of transmission line to their protected stacking with no lessening of framework steadiness and security edges.

THE expansion in power request and constrained hotspots for electric power has brought about an inexorably complex interconnected framework, compelled to work nearer to the furthest reaches of security. Voltage insecurity is fundamentally connected with responsive power awkwardness. The loadability of a transport in the power framework relies on upon the receptive power bolster that the transport can get from the framework as the framework approaches the voltage crumple point.

Investigation of responsive power affectability as a record for discovering the weakest transport. The method for discovering Voltage Stability Margin is likewise proposed [1]. At long last, a technique to repay the receptive energy of the weakest transport to enhance its dependability is likewise proposed. Possibility test is likewise done to learn at which condition the framework is more secured. These strategies are tried on the IEEE-14 transport framework and results are given to demonstrate the viability of the proposed techniques [1].

A use of ideal receptive power stream answers for summon the responsive power infusion of STATCOM. Commonly, a responsive power compensator, for example, STATCOM can be controlled by different means [2]. The ideal power stream arrangement is extremely valuable. It is a streamlining agent in which a specific target is limited while meeting all framework requirements. Arrangements of ideal receptive power streams are utilized to set as the reference to the STATCOM's controller. Be that as it may, in [2] arrangement pay system is not proposed, in 11] additionally they have said with respect to shunt pay as it were. To exhibit this control procedure, 24-hour ideal power stream arrangements of a basic three-transport test framework was utilized for test. The outcome demonstrated that responsive power pay by utilizing the ideal receptive power stream arrangement can prompt the base power misfortune operation of the whole influence framework and the framework voltage profile is level and smooth. An exertion is made to evaluate nearby and worldwide voltage security of multi-transport control framework in nearness of STATCOM and SVC [3]. A Global 
Voltage Security Indicator (GVSI) gotten from arrangement organize likeness multi-transport control framework has been utilized to evaluate general framework voltage security. In [3] Thevenin's likeness the power framework as for a specific load transport has been utilized to survey the nearby voltage security. A relative review on adequacy of STATCOM and SVC in change of voltage security utilizing system reciprocals has likewise been introduced and approved utilizing the outstanding L-file. STATCOM observed to be more successful than SVC to guarantee voltage security and in the meantime it is likewise skilled to diminish responsive electrical cable misfortune significantly. Be that as it may, in [2] a three-transport control framework was set up as an experiment for benchmarking. The outcomes demonstrated that an arrangement of ideal arrangements regarding the power transmission misfortune target can prompt the most reduced vitality misfortunes for one day operation.

An exertion is made to survey neighbourhood and worldwide voltage security of multi-transport control framework in nearness of STATCOM and SVC [3]. A Global Voltage Security Indicator (GVSI) gotten from arrangement organize likeness multi-transport control framework has been utilized to survey general framework voltage security. In [3] Thevenin's likeness the power framework concerning a specific load transport has been utilized to survey the neighbourhood voltage security. A relative review on adequacy of STATCOM and SVC in change of voltage security utilizing system counterparts has additionally been displayed and approved utilizing the outstanding L-record. STATCOM observed to be more viable than SVC to guarantee voltage security and in the meantime it is likewise proficient to lessen responsive electrical cable misfortune extensively. Yet, in [2] a three-transport control framework was built up as an experiment for benchmarking. The outcomes demonstrated that an arrangement of ideal arrangements as for the power transmission misfortune goal can prompt the most minimal vitality misfortunes for one day operation.

In vigorously stacked frameworks, voltage soundness point of confinement is normally prevailing and voltage precariousness is typically watched taking after expansive unsettling influence. This is commonly the case in the deregulated condition as the transmission frameworks are working under more focused on condition because of expanded exchange level related with open access [4]. Lately, anomalous voltage insecurity has happened in a few nations. More consideration is subsequently required to be paid to keep voltage profile and hold the voltage security under control. In [4] a straightforward voltage security investigation is completed for a multi transport control framework (26 Bus System). The impact of shunt remuneration and transformer on load tap evolving (OLTC) is built up for development of voltage dependability and framework stack capacity. Displaying and investigation of voltage security at AC compensation transport in LCC (Line commutated converters) based multi-infeed HVDC framework [5]. In [5] presents the investigation of impacts of different working control modes in HVDC and in addition area of unsettling influence on the voltage steadiness of the framework under review. Another technique for demonstrating the LCC converters as time shifting permission at the AC recompense transport is additionally displayed in [5].The displaying of STATCOM for arrangement of dynamic voltage bolster at one of the AC transports of the HVDC framework is introduced [5]. The responsive power infused by STATCOM is controlled by directing the voltage of the AC transport to which STATCOM is associated.

In current period, the power framework is winding up noticeably more intricate because of lopsided burdens and other distinctive conditions. Because of multifaceted nature of the power framework, it is extremely hard to keep up soundness and keep up framework voltage. So use of framework types of gear is impractical. Because of poor power figure at load side the voltage control deteriorates and the receptive power requested by load increments. In [6] execution of the STATCOM to make up for the receptive power requested by the heap and keep up the network responsive power close to zero, which diminishes the weight of the lattice. The traditional PI controller is utilized to produce the reference current which utilizes hysteresis current control (HCC) strategy to create the beat for 3-stage voltage source converter. MATLAB/Simulation is utilized to break down the execution. This re-enactment is done on real voltage level $(33 \mathrm{kV})$.

Voltage list is a typical and undesirable power quality wonder in the conveyance frameworks which put touchy loads under the hazard. Dynamic voltage restorer (DVR) can give [7] the most business answer for alleviate voltage hang by infusing voltage and in addition control into the framework. In [7] the use of dynamic voltage restorer (DVR) on power dispersion frameworks for alleviation of voltage hangs at basic burdens. In this paper, a diagram of the DVR, its capacities, arrangements, parts, repaying methodologies and control techniques are checked on alongside the gadget abilities and confinements.

The Dynamic Voltage Restorer (DVR) is quick, adaptable and effective answer for voltage list issue. The DVR is an arrangement compensator used to alleviate voltage lists and to re-establish stack voltage to its appraised esteem. In [8] a diagram of the DVR, its capacities, arrangements, segments, working modes, voltage infusion strategies and shut circle control of the DVR yield voltage are checked on alongside the gadget abilities and constraints. 


\section{ISO 3297:2007 Certified}

Vol. 5, Issue 5, May 2017

The Unified Power Flow Controller (UPFC) gives a promising intends to control stream in current power frameworks. Basically, the execution relies on upon appropriate control setting achievable through a power stream investigation program [9]. [9] presents a dependable strategy to meet the prerequisites by building up a Newton-Raphson based load stream computation program through which control setting of UPFC can be resolved specifically.

In this venture a voltage solidness study is done on a standard IEEE 14 transport framework. As in previously mentioned papers a large portion of the remuneration procedure is shunt pay and in a few papers arrangement pay is additionally done yet they have not utilized both in a solitary paper. In this paper both shunt pay (STATCOM) and arrangement remuneration (DVR) are utilized as repaying gadgets and results are thought about. A MATLAB program has written with a specific end goal to lead the heap stream examination by utilizing Newton Raphson technique. MATLAB/Simulation is utilized to break down the execution.

\section{ISSUE CONTENT}

Control framework is voltage stable if voltages after an unsettling influence are near voltages at ordinary working condition. A power framework ends up noticeably flimsy when voltage wildly diminishes because of blackout of gear, addition of load, decrement of creation. The heart of the voltage solidness issue is the voltage drop that happens when the power framework encounters an overwhelming burden, and one genuine kind of voltage precariousness is voltage fall. Voltage fall is portrayed by an underlying moderate dynamic decrease in the voltage extent of the power framework transports and a last fast decrease in the voltage size. Voltage insecurity can be viewed as wildness of voltage extent at various transports of a power framework. Keeping in mind the end goal to keep up voltage steadiness there ought to be legitimate stream of receptive power in the system. Keeping up appropriate receptive power in the system is a vital undertaking. Henceforth on the off chance that we neglected to keep up the receptive power stream in the circuit then voltage steadiness can't be kept up. Event of issues either inward blames or outside deficiencies will bother the voltage soundness of the framework.

\section{III.THESOLUTIONAPPROACH}

\section{A. DETERMINATION OF THE WEAKEST LOAD BUS VOLTAGE COLLAPSE POINT}

Newton-Raphson Load Flow analysis is carried out on the IEEE-14 bus system. The basic equation used in NewtonRaphson method is-

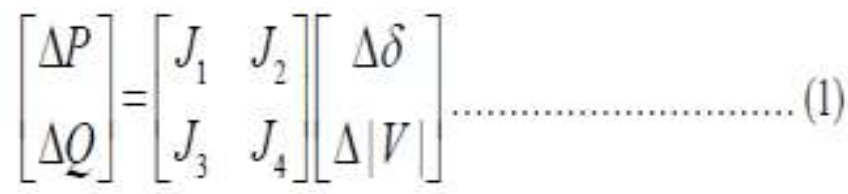

Thus, Jacobian Matrix (equation 1) is formed. Jacobian matrix ( $\mathrm{J}$ ) can be subdivided into four sub matrices- $\mathrm{J}=[\mathrm{J} 1 \mathrm{~J} 2$; J3 J4].

It is assumed that fault has occurred at bus number 7 and by the load flow studies bus 7 is treated as weakest bus.

Now, the reactive power is less sensitive to changes in phase angles and is mainly dependent on changes in voltage magnitudes. Similarly, real power change is less sensitive to the change in the voltage magnitude and is most sensitive to the change in phase angle. So, it is quite accurate to set $\mathrm{J} 2$ and $\mathrm{J} 3$ of the Jacobian matrix to zero.

The diagonal elements of $\mathrm{J} 4$ indicate the reactive power sensitivity of $\mathrm{i}$-th bus. $\partial \mathrm{Qi} / \partial|\mathrm{Vi}|$ also indicates the degree of weakness for the $\mathrm{i}$-th bus. The bus corresponding to the maximum value of $\partial \mathrm{Qi} / \partial|\mathrm{Vi}|$ is the strongest bus and the bus corresponding to the minimum value of $\partial \mathrm{Qi} / \partial|\mathrm{Vi}|$ is the weakest bus. In this way weakest load bus of any multi bus system can be found out.

\section{B. STATCOM}

The power framework is ending up noticeably more mind boggling because of lopsided burdens and other distinctive conditions. Because of many-sided quality of the power framework, it is exceptionally hard to keep up soundness and keep up framework voltage. Voltage list is a typical and undesirable power quality marvel in the dissemination frameworks which put touchy loads under the hazard. The STATCOM is a strong state shunt gadget that produces or retains responsive power and is one individual from a group of gadgets known as adaptable AC transmission framework (FACTS).Usually a STATCOM is introduced to enhance voltage soundness. Fig 1 demonstrates the controller circuit. 


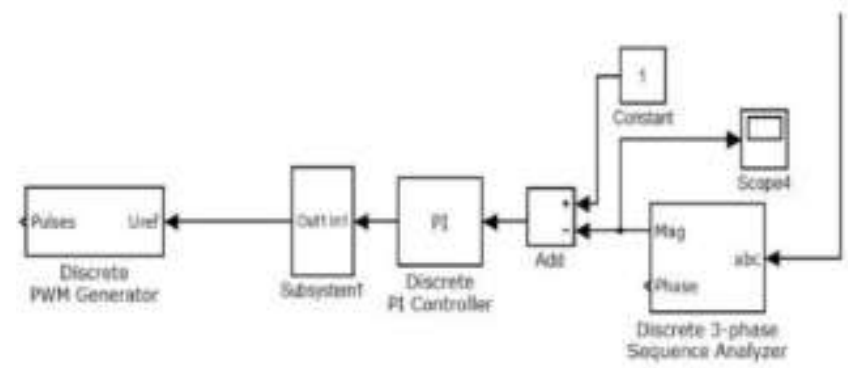

Fig 1: controller circuit

The receptive power at the terminals of the STATCOM relies on upon the adequacy of the voltage source. For instance, if the terminal voltage of the VSC is higher than the AC voltage at the purpose of association, the STATCOM creates responsive power; then again, when the plenty-fulness of the voltage source is lower than the AC voltage, it ingests receptive power. On the off chance that the yield voltage of the VSC is equivalent to the AC terminal voltage, no responsive power is conveyed to the system. Functional outline of STATCOM is appeared in fig 2.

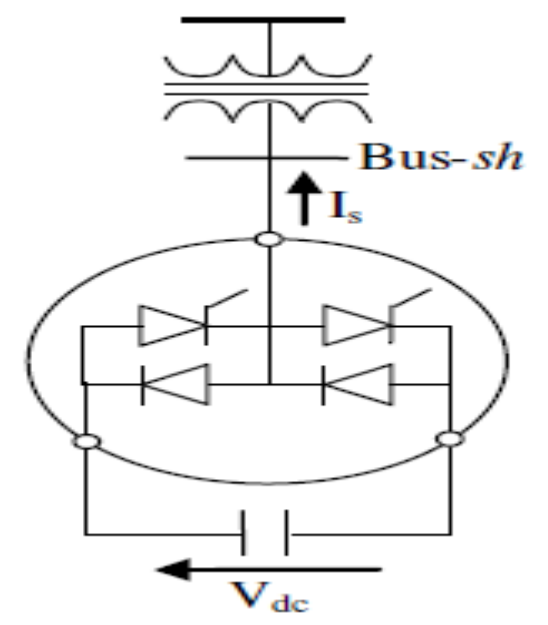

Fig 2 : Functional diagram of STATCOM

\section{B. DYNAMIC VOLTAGE RESTORER (DVR)}

The Dynamic Voltage Restorer (DVR) is fast, flexible and efficient solution to voltage sag problem. The DVR is a series compensator used to mitigate voltage sags and to restore load voltage to its rated value. Location of DVR is as shown in fig 3 .

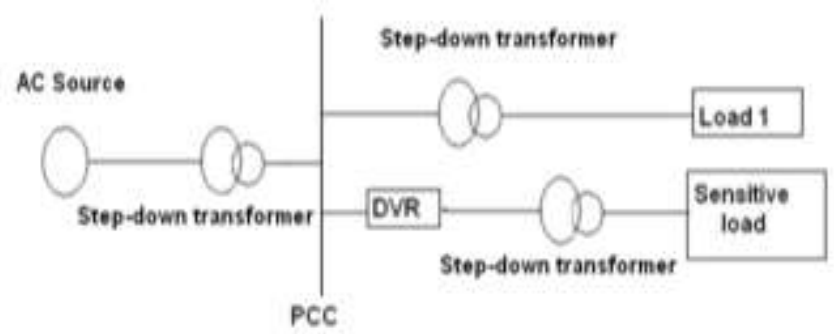

Fig. 3 Location of a dynamic voltage restorer (DVR)

A DVR is a series-connected solid-state device that injects voltage into the system in order to regulate the load side voltage. It is normally installed in a distribution system between the supply and a critical load feeder at the so-called point of common coupling (PCC).Its primary function is to rapidly boost up the load-side voltage in the event of a voltage sag in order to avoid any power disruption to that load. There are various circuit topologies and control schemes that can be used to implement a DVR. Together with voltage sags and swells compensation, DVR can also have other features like: line voltage harmonics compensation, reduction of transients in voltage and fault current limitations. Figure 4 shows the general configuration of DVR. 
International Journal of Innovative Research in Electrical, Electronics, Instrumentation and Control Engineering

ISO 3297:2007 Certified

Vol. 5, Issue 5, May 2017

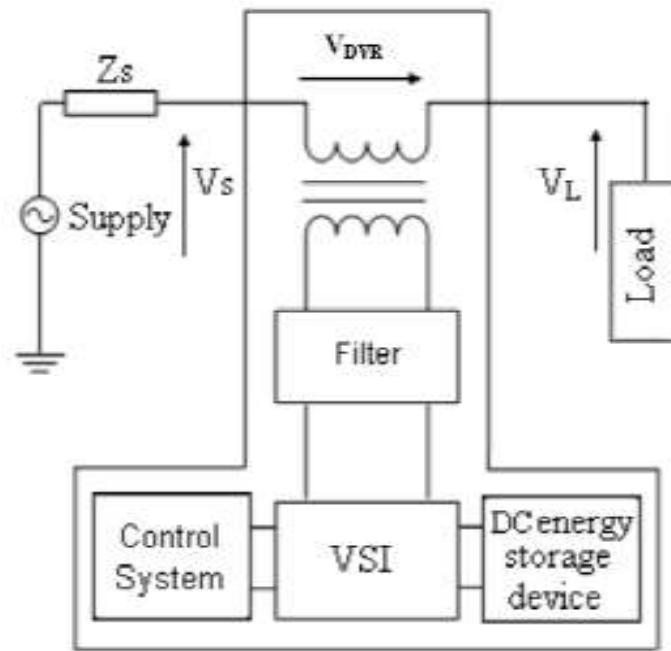

Fig. 4 Dynamic Voltage Restorer (DVR) general configuration

\section{IV.SIMULTION AND RESULTS}

A standard IEEE 14 bus system is as sg

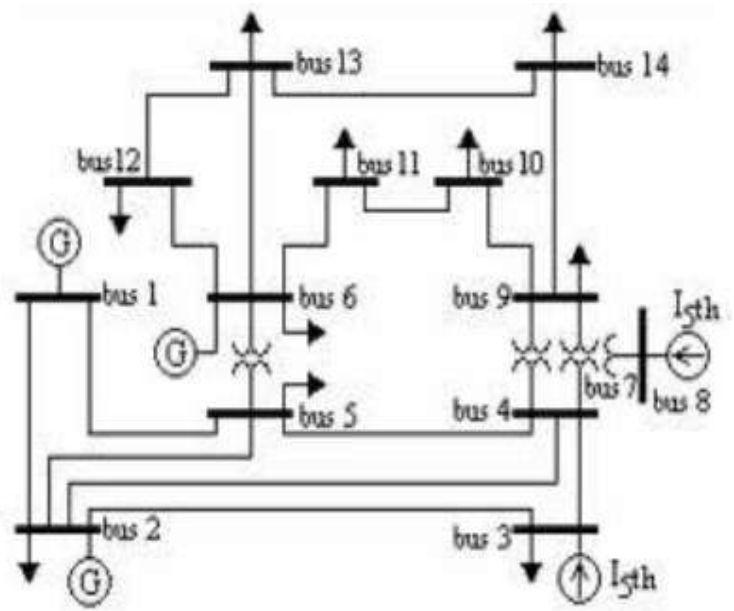

Fig 5: IEEE standard 14 bus system

1. Load flow results before fault

\begin{tabular}{|c|c|c|c|c|c|c|c|c|c|c|c|}
\hline \multicolumn{3}{|c|}{ Acdipebabe BaD } & \multicolumn{3}{|c|}{ Itat Hived ina lasget bey } & $P M$ & \multicolumn{3}{|c|}{ QN6- Qhin Ual Qhalla: } & \multicolumn{2}{|c|}{ 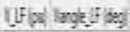 } \\
\hline $1 \mathrm{Sa}$ & - & $\mathrm{BSE}:$ & 0.90 & 1 & 0.00 & C.n? & a.x & 0.00 & $2 \mathrm{~m}$ & 1.:a & -2.12 \\
\hline $2 \mathrm{x}$ & & 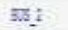 & a. & & $m$ & cos & 1.2 & - The & $=$ & 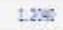 & $12:$ \\
\hline In & & $3 E_{-}$ & & & & ons & 4.2 & & & ta & -36. \\
\hline If tas & & 56,12 & & & o & w & $t, 2$ & & & & 53.8 \\
\hline 5 Ix tond & & 305.11 & 0,90 & & 0.0 & en: & t.x & - Int & at & $\mathrm{s}: 5$ & $-\leqslant 2.4$ \\
\hline Ix thes & & 35,16 & 28 & & a & cos. & 1.2 & $-\mathrm{I}$ & $=$ & 1.33 & -1298. \\
\hline $7 \mathrm{HL}$ tes & & 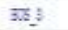 & & & in & on & 4.2 & & & $14:$ & $-2:$ \\
\hline TI Les & & sabs: & & & 20 & Co: & -1.2. & - In & $=$ & 1.486 & $-11: 1$ \\
\hline IX tans & & $\mathrm{SBE}$ & & & 8 & ent & $6 x$ & - in & f & 1.4t & 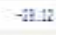 \\
\hline II Las & & $3 x, E$ & 2. & & 0 & an & . 1. & - & $\Rightarrow=$ & $17:$ & -116.4 \\
\hline $\mathrm{Ba}$ & - & 3E: & an & 1 & 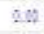 & ons & 4.2 & A. & $2 m$ & $1: 342$ & -99.6 \\
\hline $2 \mathrm{ks}$ & - & sw!: & & & $\theta$ & * & t, E & & $m$ & $14: 35$ & thes \\
\hline int & & 305 & 0. & & 0.00 & an: & t.x & $-i n g$ & inf & 1.35 & $-16: 35$ \\
\hline Tyises & & 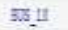 & 2.00 & 1 & 20 & a.s. & 1.2 & -Ifif & $=$ & $1 \mathrm{ata}$ & 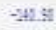 \\
\hline 15 tant & $\pi$ & $\%$ & 0. & & 10 & o.s & 4. 2 & $\therefore 0$ & $2 m$ & 1. 1634 & -1321 \\
\hline taxe: & T) & $\hat{i}$ & & & 20 & a. & 2. 2 & $\triangle B$ & 60 & 1.438: & - its. A \\
\hline $\tan$ & $\pi$ & 4 & & & & ant & t.s. & -2 & & 8 & $43 x$ \\
\hline tars & $\pi$ & 4 & 2. & 1 & 20 & cos & z.. & a. & 200 & $1 \mathrm{mE}$ & $-\mathrm{m} . \mathrm{m}$ \\
\hline fans & $\operatorname{tring}$ & 5 & 0.00 & 1 & an & on & $\div .2$ & 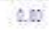 & $2 m$ & & 18 \\
\hline
\end{tabular}


2. Voltage at bus num 7 before fault

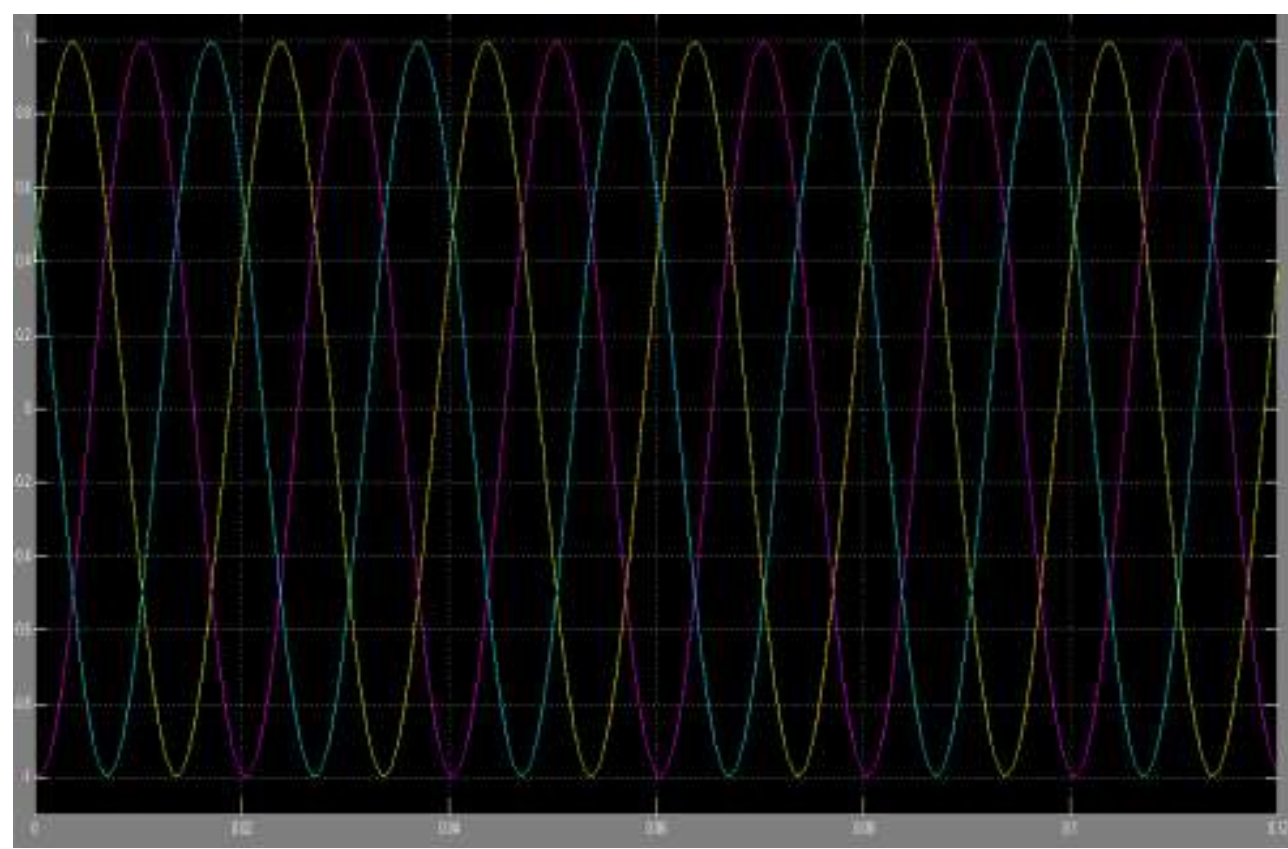

3. Load flow results after fault

\begin{tabular}{|c|c|c|c|c|c|c|c|c|c|c|}
\hline \multicolumn{3}{|c|}{ Edodgeistye bill } & \multicolumn{6}{|c|}{ 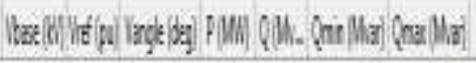 } & \multicolumn{2}{|c|}{ 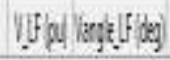 } \\
\hline $8 s$ & & $3 \pi !$ & O. & & 10. & o.M L... & 10. & 1.0 .0 & A. & -41.2 \\
\hline$\%$ & & $318:$ & in & 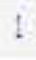 & 1.9 & A.I. I.:I & . & aif & 1.: & 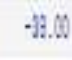 \\
\hline$z 0$ & & 3511 & . & ${ }^{*}$ & 1.0. & Q.fl I... & 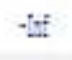 & inf & $\therefore$ & 21.37 \\
\hline Qt & & 32: $: 2$ & . & i. & 10.1 & A. IH & 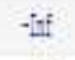 & If & $1 \%$ & III.5. \\
\hline II: & & $3 \pi 3$ & 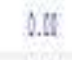 & ${ }^{*}$ & 10.1 & o... I... & - & If & L.: & III:.: \\
\hline $\mathbb{Z}$ & & $36: 14$ & m & . & 1... & A.t. $\mathrm{lm}$ & & In & L.: & 23.4 \\
\hline zec & & $30: 3$ & a.t. & ! & 100 & o.fl l. In & -8 & If: & 1.: & $\therefore \%$ \\
\hline Qt: & & 3754 & ti: & ! & 10.0 & $\Delta u \cdot u$ & - & in & 1.8 & 263.3 \\
\hline EI & & $3 \pi 5:$ & it & ? & 1.1)$. & 0.41. & - & In & 1.1 & 13. 20 \\
\hline$\pi$ & & 386 & & ${ }^{2}$ & 1.0 & A.ll $\quad$ LI: & & In & 1.8 & 14.2 \\
\hline 8 & & $35:$ & 4 & '. & 1 & An & & 1.00 & & 5.5 \\
\hline is & 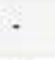 & $32.8:$ & & . & 10.0 & LII IH & & ע. & & 23.: \\
\hline $3 \%$ & & $3 \pi: 9$ & & . & $1 \%$ & ou In & & if & 80 & 2.14 \\
\hline 100 & & 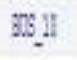 & & . & $3 m$ & An In & & af & 10 & 25.4. \\
\hline Tem & I & $\eta$ & " & : & 100 & o.te I.. & -1.00 & 1.00 & ani? & 4.98 \\
\hline Ne: & $\pi$ & $\hat{2}$ & A.I. & ! & 10.0 & A.E U. U. & (M.) & 190 & $12 \pi 5$ & -12.18 \\
\hline Hen: & Triag & $\theta$ & o. & $!$ & 1.10 & o. $\ldots . .$. & 1.0. & 1.0 & 1 & 10 \\
\hline fax: & $\pi$ & $\psi$ & A. & ! & 1.0 .8 & A.H I.U. & -1.08 & A...8 & 1460 & -2.2 .3 \\
\hline $\mathrm{ven}$ & II & $5+$ & o... & : & 10.0 & o.t. a.4. & -100 & 1000 & $1 \%$ & $\because$ \\
\hline
\end{tabular}


International Journal of Innovative Research in Electrical, Electronics, Instrumentation and Control Engineering

ISO 3297:2007 Certified

Vol. 5, Issue 5, May 2017

4. voltage at bus number 7 after fault

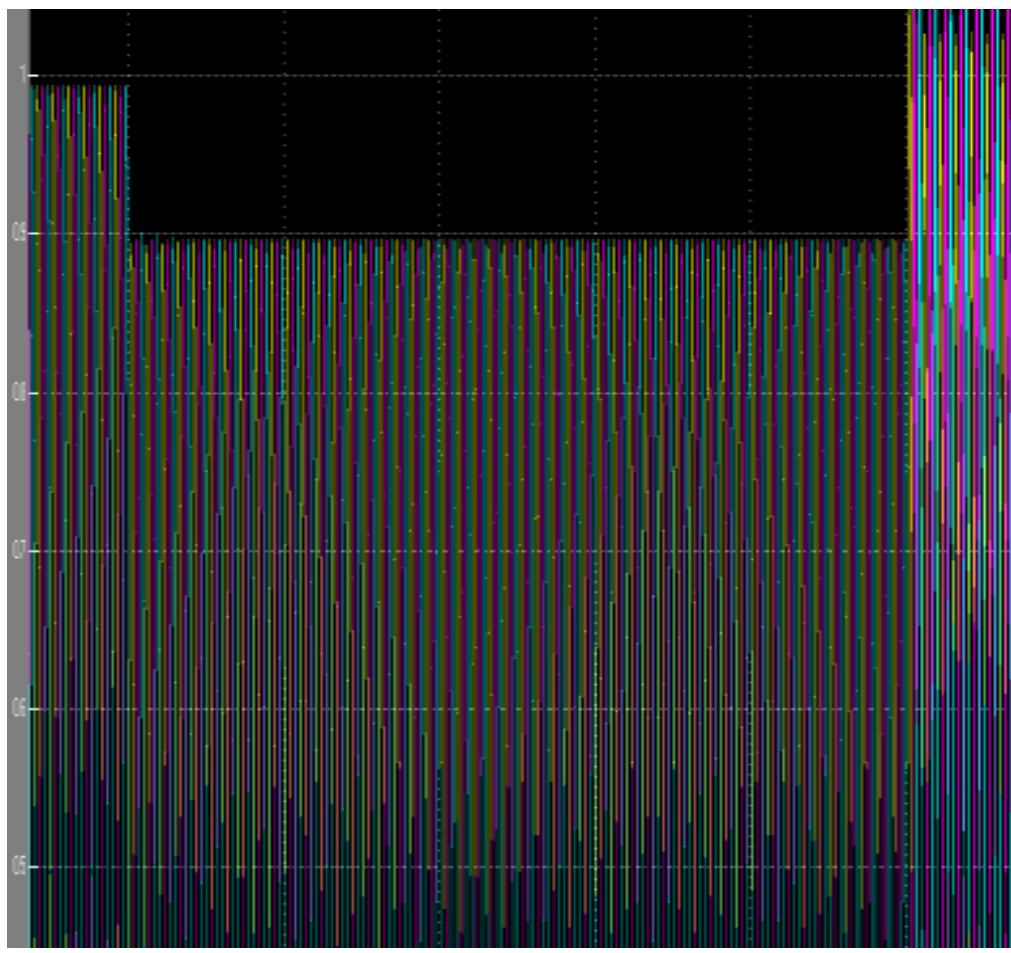

5. Load flow study after connecting DVR

\begin{tabular}{|c|c|c|c|c|c|c|c|c|c|c|}
\hline \multicolumn{11}{|c|}{ 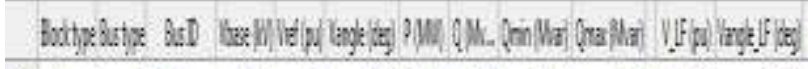 } \\
\hline 135 & $\pi ! 1$ & in & , & a. & 10.0 & $M$ & I.1. & In & $\cos 2$ & 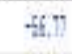 \\
\hline 2 ICtain, & $3:$ : & LiN & . & 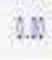 & A.M. & as & inf & iff & W2 & 45.15 \\
\hline $3 \pi \cos 2 \pi$ & 3.1. & 10 & 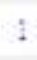 & $m$ & $\alpha O$ & $M$ & . & $n$ & 15 & U. \\
\hline 1 Wicat? & 35.12 & tis & I & A.:A & AN & 4 & . & 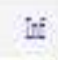 & 18 & $\pi$ \\
\hline 5 IIC irais) & 죠묘 & IU & . & a. & M. & $M$ & $\rightarrow$ & $\therefore$ & 17 & 6.9 \\
\hline i reiken? & $35 !$ & Lin & . & a.m. & o. & a & -Iff & Iff & 111 & 2.5 \\
\hline 1 Hats & 39. & M & 1 & $m$ & $\omega$ & & 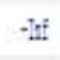 & $n$ & & 4...2 \\
\hline 1 W wasi? & $35 !$ & $\ldots$ & ${ }^{\circ}$ & (1.). & AN - & $4 i$ & 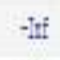 & if & 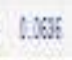 & 10 8 \\
\hline 1) IC tad: & 3!: & tiv & 1 & a. & M.8. & $M$ & -inf & it & 611 & 1196 \\
\hline 11 Tritain, & 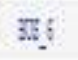 & & 2 & 2.3 & AN & & & iff & & 74 \\
\hline II: & s: & . & 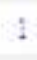 & 2.2 & 0.2 & $M$ & a.n & an & : & $10 . \mathrm{A}$ \\
\hline 118. & 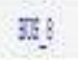 & OR & \& & 2... & A. & & 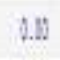 & I. & & 1 \\
\hline B $20 . \operatorname{las} 2)$ & 중 & L. & - & a... & $M$ & $M$ & - & If & 0 & 74.4 \\
\hline 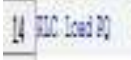 & $3: 11$ & nu. & . & 2.1. & AN & A & 1. & ift & $4 \%$ & $\pi .4$ \\
\hline fart sis & 97 & 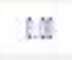 & 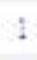 & an & Q. & $\therefore$ & 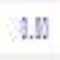 & . & & A... \\
\hline Tex & $\%$ & III & : & (2.2. & 0.8 & an & 4.1 .1 & I. & $1 \%$ & -7.46 \\
\hline $17 \mathrm{Tex} \pi$ & $\%$ & Ui & 1 & a.: & MON : & $\ddot{z}:$ & a.n & I. & ay: & -14.6 \\
\hline $1 \mathrm{Tin} \quad \mathbb{1}$ & t & t... & 2 & 2.1. & OM & Q & $\ldots$ & 7.t. & & 1... \\
\hline ast $\mathbb{\pi}$ & 5 & M & : & & D. $:$ & I.E & A.L. & 100 & ans & $4 . .9$ \\
\hline
\end{tabular}


6. Voltage at bus number 7 after connecting DVR

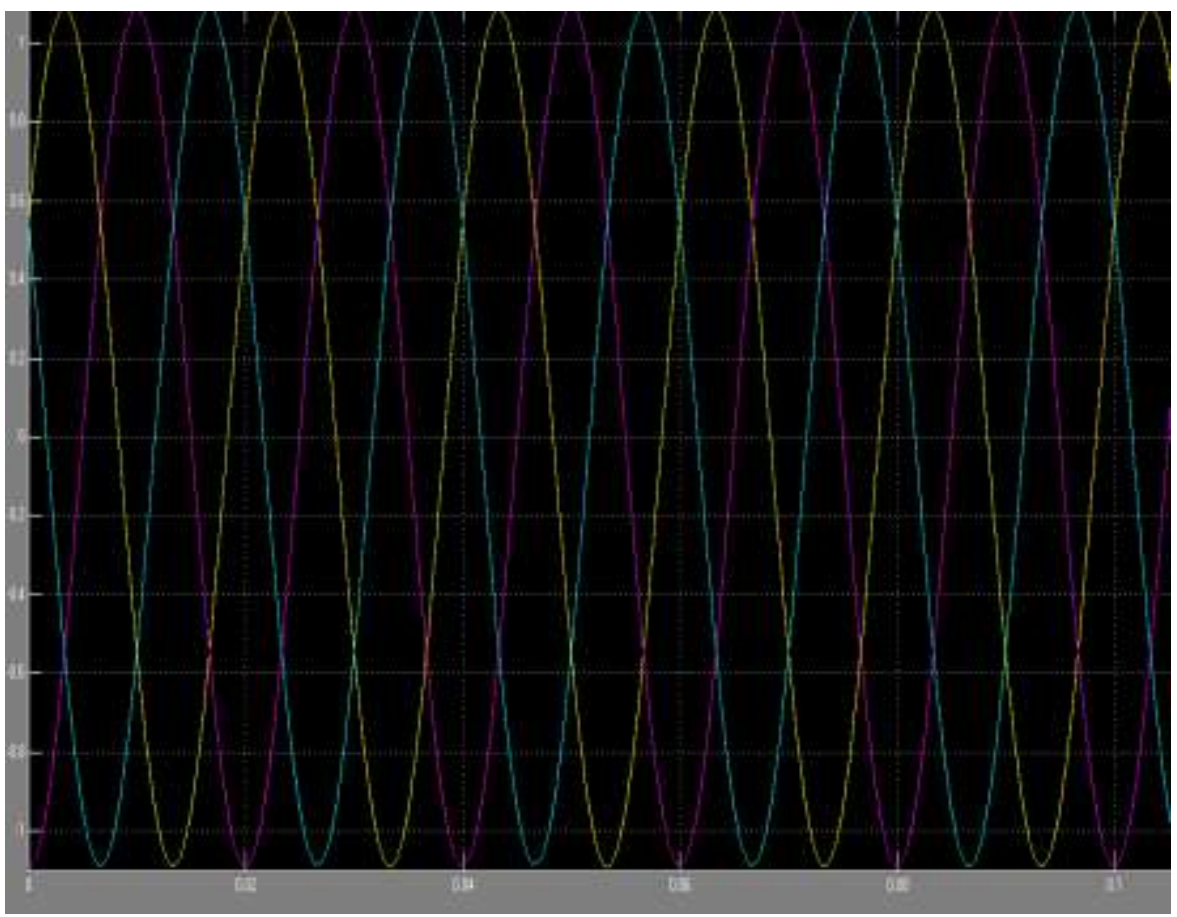

7. Load flow studies after connecting STATCOM

\begin{tabular}{|c|c|c|c|c|c|c|c|c|c|c|c|}
\hline \multicolumn{3}{|c|}{ 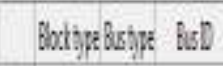 } & \multicolumn{7}{|c|}{ 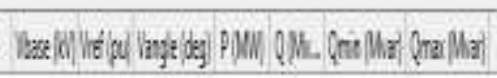 } & \multicolumn{2}{|c|}{ Vif pas lavelfidey) } \\
\hline $13 n$ & & 35.1 & Q.AI & : & 0.00 & $0.0 \%$ & 0.00 & In & 0.00 & L.Jï & -31.54 \\
\hline $2 \times 1 \ln$ & & $33:$ & o.til & 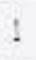 & 0.00 & 0.00 & 0.00 & -iff & int & 1.263 & -46.82 \\
\hline $3 \times 1$ ins & & 35.11 & 0.11 & ${ }^{\circ}$ & D.M. & a... & 1.0 & inf & Int & 1.25 & 17.8 \\
\hline 4 Sinas & & 33.12 & u.t: & $\therefore$ & 0.0 & 0.00 & 0.00 & $\therefore$ If & $\ln { }^{2}$ & : $\mathrm{flE}$ & 39.56 \\
\hline $5 * 10 \mathrm{~L}$ & & 38.18 & a.t. & 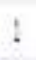 & 0.00 & 8.98 & 0.60 & $\therefore$ & trt & L.9. & M.1: \\
\hline 6 Wines & & 33.14 & o.tu & & 0...0 & 0.00 & 0.80 & inf & int & L.954 & m.7 \\
\hline 1 W ine & & 35.3 & o.t. & . & 0.0 & a. & 0.0 & inf & Int & Wh: & $-i 3 .:$ \\
\hline 8 Wines & & $53 !$ & a.t. & 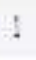 & 0.0 & OM. & -4.0 & $-i f$ & $\ln { }^{2}$ & A.ms & 23.9 \\
\hline $9 \approx 1 \mathrm{Ca}$ & & $35:$ & Q.AI & 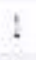 & 2.00 & $0.0 \%$ & 0.6 & -ifl & in: & $m$ & 34.81 \\
\hline I) $\approx$ inas & & 376 & o.tI & . & 0.0. & 0.00 & 1.0 & -if & Int & L.S3I & 10.91 \\
\hline 11323 & & 35. & 0.11 & ${ }^{\circ}$ & $\$ . .0$ & 0.0 & 0.0 & I.I. & 0.00 & 1200 & 43.01 \\
\hline $123 s$ & . & 338 & a.l. & 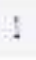 & 0.0 & $O M$ & $A .00$ & $1 . M$ & 0.00 & 1 & $-3 . .8$ \\
\hline B $3 \mathrm{C}$ & & 35:? & Q:AI & $0^{\circ}$ & 2.00 & 6.08 & 0.00 & -iff & $i n$ & 100 & 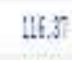 \\
\hline If X Ina: & & 35.10 & o.t. & . & 0.0. & 0.00 & 0.0 & -if & Itr & $1 . \% \mathrm{O}$ & 12.4 \\
\hline $15 \pi \mathrm{ksc}$ & $s x$ & 16 & 0.11 & . & 0.00 & 0.00 & 1.0 .0 & I.I. & 0.00 & 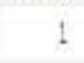 & 1.0. \\
\hline $18 \mathrm{rasc}$ & II & $r$ & 0.11 & 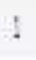 & 0.0 & 0.00 & 0.0 & -1.11 & 0.00 & $1 M B$ & -57.93 \\
\hline 17 hast & $\eta$ & $\vec{s}$ & Q.II & ${ }^{\circ}$ & 1.00 & 0.0.: & (3...) & $1 . M$ & 0.00 & 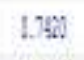 & -11.3. \\
\hline 18 lase & $n$ & tै: & o.t. & $:$ & 0.00 & 0.00 & 1.00 & I.M & 0.00 & 1.932 & -1.7 \\
\hline Q iste & $\pi$ & 5 & 0.11 & $\cdot$ & 0.00 & $0.00:$ & (2.. .8 & -1.1 & 0.00 & 1315 & 7.4 \\
\hline
\end{tabular}




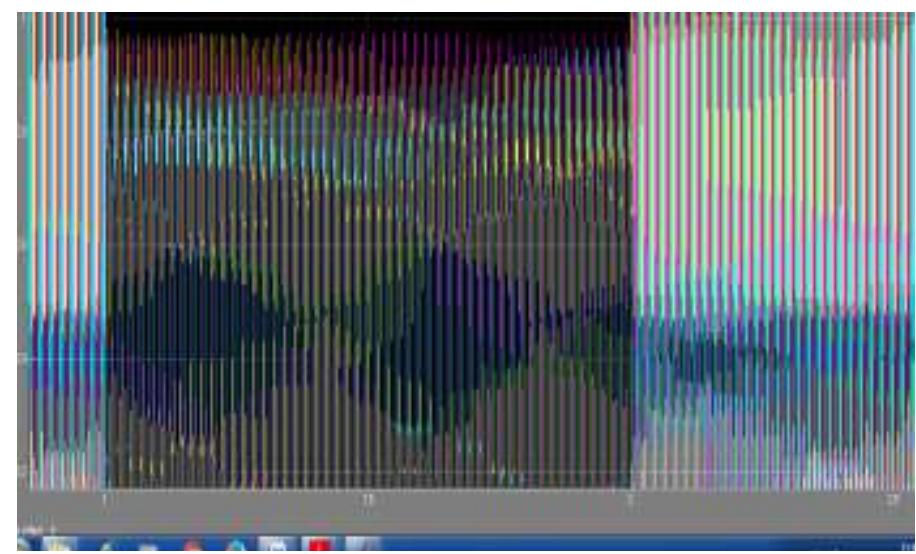

\section{CONCLUSION}

If we compare the status of compensated and uncompensated 14th bus it is seen that the power transfer capability of the bus has been increased after the addition of STATCOM and DVR. Fourteen bus system is modelled and simulated using MATLAB SIMULINK. The simulation results of fourteen bus system with and without VSI based D-STATCOM and DVR are presented. Also, simulation of fourteen bus system with and without D-STATCOM and DVR is done. STATCOM and DVR systems are compared. Voltage stability is improved by using both D-STATCOM and DVR. This system has improved reliability and power quality. The simulation results are in line with predictions. The scope of present work is the modelling and simulation of eight bus system and compared. This concept can be extended to 64 bus system.

\section{ACKNOWLEDGMENT}

I am extremely grateful to my guide Dr. D. Sathyanarayana professor at the power system Department, University of BDT college engineering and for extending all its facilities. I am humbly extend my sense of gratitude to my faculty members, laboratory staffs, library staffs and administration of this institute for providing me their valuable help and time in congenial working environment.

\section{REFERENCES}

1. Maximum Loading Point (MLP) and Voltage Stability Margin (VSM) Of A Multi-Bus System Before and After Compensation by , Chandramouli Gupta, Sumana Chowdhuri, Sourav Basu.

2. Control of STATCOM by Using Optimal Reactive Power Flow methods by D. U. Kwannetr, and T. Kulworawanichpong, Uthitsunthorn, . Sinsuphun, NU. Leeton.

3. A Comparative Study in Improvement of Voltage Security in A Multi-Bus Power System Using STATCOM and SVC by Sunita Halder nee Dey, Member, IEEE and Tanaya Datta Priyanath Das Abhijit Chakrabarti .

4. Improvement of Voltage Stability by OLTC and Shunt Compensation in Large Multibus Power System by S.D.Naik M.K.Khedkar S.S.Bhat.

5. Analysis of voltage stability in multi-infeed HVDC systems with STATCOM by K.R.Padiyar and K Saichand, Senior member,IEEE Department of Electrical engineering Indian Institute of Science.

6. Reactive Power Compensation Using Static Synchronous Compensator (STATCOM) with Conventional Control Connected with 33kV Grid by Meenakshi Rastogi and Abdul Hamid Bhat

7. Conventional dynamic voltage restorer (dvr) for mitigation of voltage sag in power distribution systems by A. Mohammed, Abdel-Moamen M. A, B. Hasanin, Shazly, Aurelio G. Cerrada..

8. Dynamic Voltage Restorer (DVR) System for Compensation of Voltage Sags, State-of-the-Art Review by A. Mohammed, Shazly, AbdelMoamen M. A, Aurelio G. Cerrada and B. Hasanin.

9. Dynamic Voltage Restorer (DVR) for Voltage Sag Mitigation by Mahmoud A. El-Shennawy , Amr Y. Abou-Ghazala, and Tarek I. El-Gammal.

10. Design and Control of Single Phase Dynamic Voltage Restorer by Yogesh Sonawane and Sanjay Tungare, Shirazul Islam, Sandeep Anand and Amit Meena.

\section{BIOGRAPHIES}

B Venkateshnaik Student, Power System Department, University of BDT College of engineering, Davanagere, India.

Dr. D. Sathyanarayana Professor Power System Department, University of BDT College of engineering, Davanagere, India. 